\title{
Estimation of serum haemoglobin-binding capacity (haptoglobin) on Sephadex G.100
}

\author{
A. P. RATCLIFF AND J. HARDWICKE \\ From the Department of Experimental Pathology, \\ Birmingham University Medical School
}

SYNOPSIS A method is described for the estimation of serum haptoglobin as 'haemoglobin-binding $\vec{v}$ capacity'. The method relies on column chromatographic separation of the haemoglobin/haptoglobin complex from excess added free haemoglobin on the dextran gel Sephadex G.100. The $\partial$ method is simple and reproducible, and correlates well with another method of estimating haemoglobin-binding capacity over a wide range of values.

The estimation of serum haptoglobin is of principal value in the detection of minor degrees of haemolytic disease (Neale, Aber, and Northam, 1958). Several methods have been described, based on measurement of the peroxidase activity of the haemoglobin/ haptoglobin complex, both titrimetric (Jayle, 1951) and colorimetric (Connell and Smithies, 1959), or on the determination of the haemoglobin-binding capacity of the haptoglobin by titration with haemoglobin, followed by electrophoresis on filter paper (Laurell and Nyman, 1957) or in agar gel (Rowe, 1961) to determine the end point at which 'uncombined haemoglobin' is just demonstrable.

This paper reports a simple alternative method based on the separation of the high molecular weight haemoglobin/haptoglobin complex, formed by the addition of excess haemoglobin solution to the serum, from the lower molecular weight uncomplexed 'free haemoglobin'. This separation is effected by gel filtration on Sephadex G.100, followed by elution with $2 \mathrm{~g} . \%$ sodium chloride solution.

APPARATUS AND REAGENTS

COLUMN Sephadex G.100 (Pharmacia ${ }^{1}, 140-400$ mesh) was suspended in an excess of $2 \mathrm{~g} . / 100 \mathrm{ml}$. sodium chloride solution. After standing for 24 hours to allow full swelling of the gel, the suspension was poured into a glass column $40 \times 1 \frac{1}{2} \mathrm{~cm}$. and allowed to pack under gravity, leaving about 1 in. of solvent above the column. Each column requires 7 to $8 \mathrm{~g}$. dry resin. The column is then connected to a reservoir of eluting fluid $(2 \% \mathrm{NaCl})$ and washed for 12 hours before use.

Coarse ground glass, prepared by grinding up Pyrex

'Pharmacia (Gt. Britain) Ltd., Sinclair House, The Avenue, West Ealing, London, W.13.

Received for publication 10 January 1964. test tubes in a mortar and washing out the finely powdered $\Phi$ fraction, is a satisfactory material for padding the bottom $\frac{3}{0}$ $\frac{1}{4}$ in. of the column; a filter bed is formed by allowing $\stackrel{\mathbb{Q}}{-}$ this powdered glass to sediment through water in the $\vec{P}$ column. A similar thin layer ( $\frac{1}{16}$ in.) of glass powder on $\mathscr{O}$ the top of the packed gel facilitates the layering on of $\perp$ samples without stirring up the upper surface of the gel. If glass wool is used to retain the gel, it readily becomes? clogged by the fine gel particles, giving very slow flow rates.

STANDARD HAEMOGLOBIN SOLUTION This was prepared $\stackrel{\mathbb{Q}}{\unrhd}$ from freshly drawn normal adult blood by the method of $\overrightarrow{\overrightarrow{0}}$ Dacie (1956), and, when standardized against a Keeler 3 neutral grey solution, contained $13.5 \mathrm{~g}$. haemoglobin $/ \supset$ $100 \mathrm{ml}$. A range of dilutions from 0.01 to $0.1 \mathrm{mg} . / \mathrm{ml}$. was prepared, and the extinctions measured at $415 \mathrm{m \mu}$ using a Unicam S.P.500 spectrophotometer, and $10 \mathrm{~mm} . \overline{0}$ glass cells. A straight line calibration curve was obtained from these dilutions. The concentrated haemoglobin solution was divided into $1 \mathrm{ml}$. aliquots and sorted at $\not$ $-20^{\circ} \mathrm{C}$., fresh tubes being used as required for the $\frac{0}{3}$ analyses.

METHOD

Of the standard haemoglobin solution, $0.02 \mathrm{ml}(=2.7 \mathrm{~N}$ $\mathrm{mg}$. $\mathrm{Hb}$ ) is added to $0.5 \mathrm{ml}$. of serum. Approximately$5 \mathrm{mg}$. of solid sodium chloride is added to this mixture 0 to increase the specific gravity, and the serum is layeredN directly on to the Sephadex column below the saline $\sigma$ supernatant. The column is eluted with 2 g./100 ml: sodium chloride solution at the rate of approximately 15 drops per minute, $2 \mathrm{ml}$. fractions being collected on a siphon fraction collector: at this speed a column is fully: eluted in two and a half hours. The extinctions of the? fractions are measured at $415 \mathrm{~m} \mu$, using a Unicam울

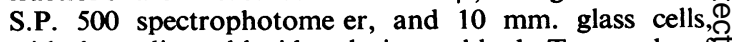
with the sodium chloride solution as blank. Two peaks of colour are obtained (Fig. 1): the first usually comprises 


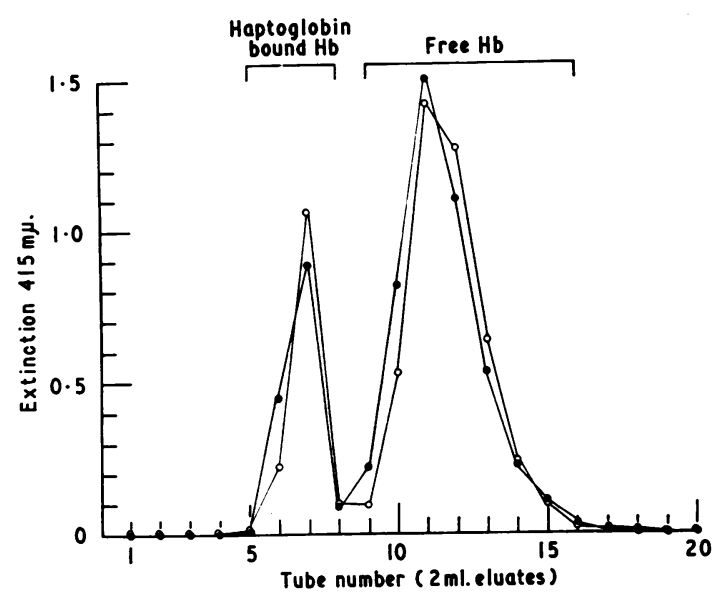

FIG. 1. Duplicate separations of haemoglobin-haptoglobin complex from free haemoglobin on Sephadex G.100 column.

Sephadex G.100 column $\left(40 \times 1 \frac{1}{2} \mathrm{~cm}.\right) .0 .5 \mathrm{ml}$. serum + $0.02 \mathrm{ml}$. haemoglobin solution $(=2.7 \mathrm{mg} . \mathrm{Hb})+5 \mathrm{mg}$. sodium chloride, eluted with sodium chloride solution (2g./100 ml.).

about five $2 \mathrm{ml}$. fractions, and is followed by a second more diffuse peak. The fractions from the first peak are pooled and the extinction measured in the same way as before. Haemoglobin concentration in this pool is read off from the calibration chart, and the total haemoglobin in peak 1 calculated $(\mathrm{Hb}$ concentration in $\mathrm{mg} . / \mathrm{ml}$. $\times$ volume of pool).

Haptoglobin concentration is then expressed as haemoglobin-binding capacity of peak 1 in $\mathrm{mg} . / 100 \mathrm{ml}$. serum $=$ total haemoglobin in peak $1 \times \frac{100}{0.5}$. After washing out the free haemoglobin the column is ready for re-use. A single column can be used repeatedly, and we have used them for up to 30 estimations.

\section{SPECIFICITY OF ESTIMATION OF HAPTOGLOBIN}

The haptoglobins are the only class of serum proteins conclusively shown to combine with haemoglobin.

Haematin will combine with haemopexin, a $\beta$-globulin of low molecular weight, and with albumin, the latter giving methaemalbumin, but has not been shown to combine with haptoglobin. Conversion of haemoglobin to haematin occurs when free haemoglobin, in serum, is incubated at $37^{\circ} \mathrm{C}$.; when free haemoglobin is present in the circulation; and also when haemoglobin is passed through some supporting media, such as paper in electrophoresis, or starch in column chromatography (Aber and Rowe, 1960). Such conversion has not been found on Sephadex columns.

These haematin protein complexes both give a positive Schumm reaction, and have characteristic absorption spectra. Schumm tests were negative on both elution peaks in this method, and spectral absorption curves showed the presence of reduced haemoglobin only. Orthotolidine staining of peak 1 after electrophoresis at $p \mathrm{H} \mathrm{8.7}$ in parallel with the whole serum showed only one band of staining in the alpha ${ }_{2}$ region (Fig. 2). It can therefore be concluded that the method estimates only haptoglobin-bound haemoglobin.

In highly lipaemic sera the peak 1 is sometimes turbid. This will result in falsely high readings at $O D_{415}$; fasting blood samples are therefore preferable. Freeman (personal communication) has overcome this difficulty by complexing the serum with haemoglobin in which the iron is isotopically labelled, and counting the label in peak 1 .

\section{RESULTS}

NORMAL SERA Twenty-seven pairs of duplicate estimations were performed, the individual values of Hb-binding capacity varying from 20 to $200 \mathrm{mg}$./100 $\mathrm{ml}$. The standard deviation of the method was calculated from these paired estimations, and was $\pm 7.04 \mathrm{mg}$. Hb-binding/100 ml. serum. The normal range was determined by measuring the haptoglobin content of 40 sera from blood donors, comprising 20 males and 20 females (Table I).

A significant difference was found on applying Student's $t$ test to these two groups.

$$
\mathrm{t}=3.29 \quad \mathrm{p}=0.01-0.001 \text {. }
$$

\section{TABLE I}

\begin{tabular}{llll} 
& \multicolumn{4}{c}{ HB-BINDING CAPACITY IN NORMALS } \\
& Total & Male & Female \\
\cline { 2 - 4 } No. of sera tested & 40 & 20 & 20 \\
\hline Range & $45 \cdot 8-150$ & $59 \cdot 5-150$ & $45 \cdot 8-127$ \\
Mean & $94 \cdot 7$ & $106 \cdot 8$ & $82 \cdot 7$ \\
S.D. & - & $\pm 25 \cdot 85$ & $\pm 20 \cdot 2$
\end{tabular}

PATHOLOGICAL SERA Twenty sera were estimated in parallel with the method of Rowe (1961). This latter method will only estimate in the range 20 to $200 \mathrm{mg}$. $\mathrm{Hb}$-binding-capacity $/ 100 \mathrm{ml}$. Within this range the values correlate well (Fig. 3) (correlation coefficient $r=0.196, p=<0.001)$ showing that the two methods are comparable. The column method, however, using the technique described here, is applicable over a fuller range of 0 to $5,400 \mathrm{mg} . / 100$ $\mathrm{ml}$.

\section{DISCUSSION}

These results suggest that the method described affords an accurate measurement of haemoglobinbinding capacity. It has the additional advantage over two of the other methods (Jayle, 1951; Rowe, 1961) that haemolysis in the serum sample does not vitiate the analysis, and over the third (Connell and Smithies, 1959) of simplicity of operation. 


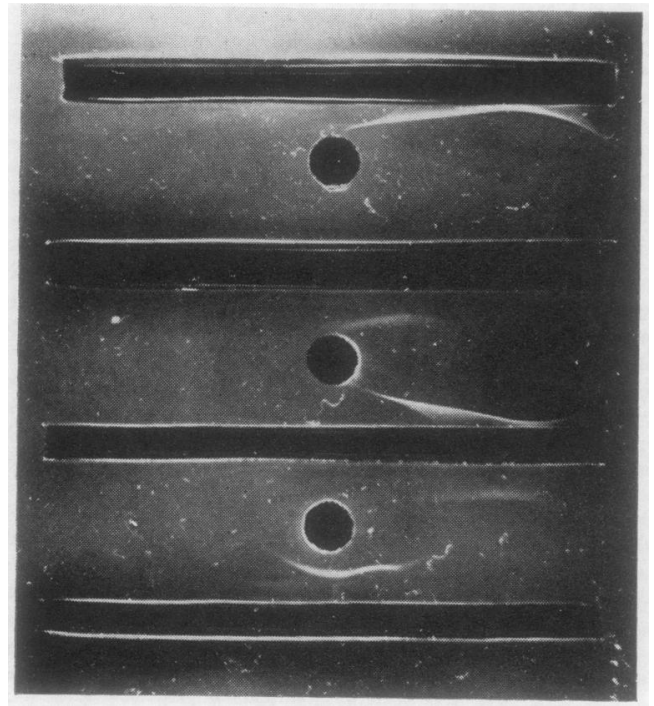

FIG. 2a

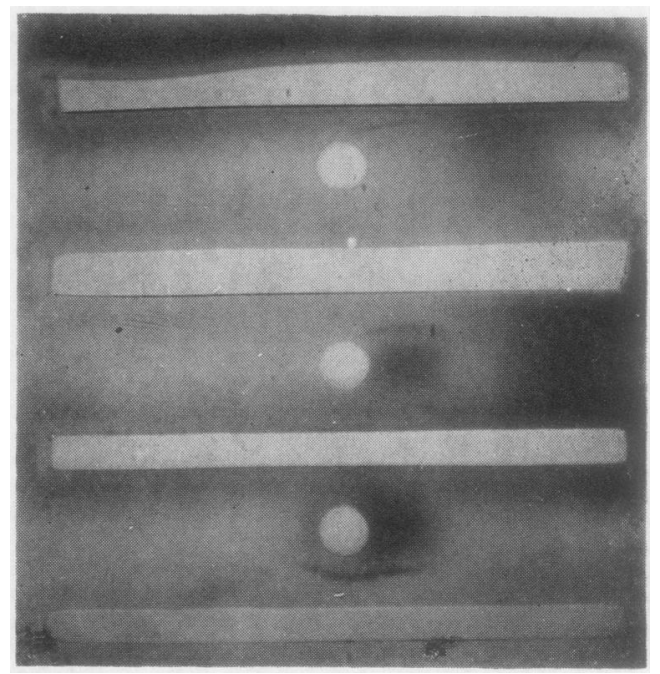

FIG. $2 b$

FIG. 2. Immunoelectrophoretic identification of haptoglobin in peak 1.

(a)

AH $\begin{aligned} & \text { Unstained } \\ & \text { AA } A H \quad A A\end{aligned}$

(b)

Orthotolidine Stain

$A H \quad A A \quad A H \quad A A$

Pk $1 \quad N S \quad P k 2$

$A H=$ antihaptoglobin antiserum. $A A=$ antialbumin antiserum. $N S=$ normal serum. $P k 1$ and $P k 2=$ elution peaks $\frac{\otimes}{\varnothing}$ at $O D_{415}$ of the normal serum on $G .100$ as in text.

Immunoelectrophoresis in agar gel at $\mathrm{pH} 8.4$. The normal serum shows both albumin and haptoglobin precipitates. Peak $2 \overrightarrow{\overrightarrow{0}}$ contains albumin but no haptoglobin. Peak 1 contains a strong haptoglobin but only a trace of albumin (the method is $Э$ sensitive to $1 \mu \mathrm{g} . / \mathrm{ml}$.). Orthotolidine staining shows haptoglobin-haemoglobin complex faintly in the normal serum but $\supset$ a strong band in peak 1. No haptoglobin present in peak 2. Note the slower electrophoretic mobility of the saturated haptoglobin-haemoglobin complex in peak 1 compared with the unsaturated haptoglobin in the whole serum.

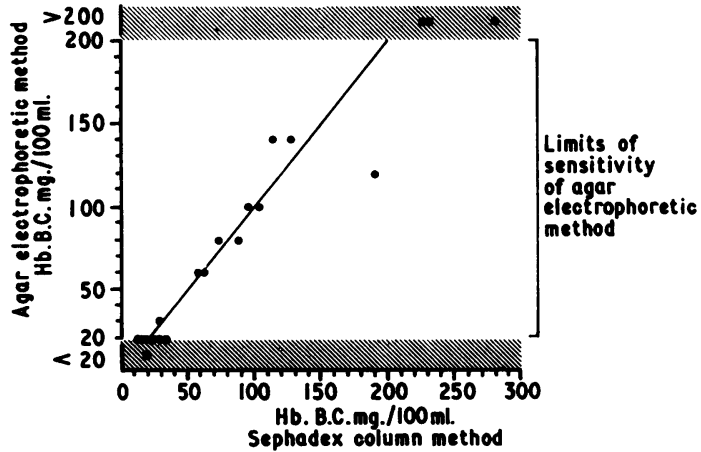

FIG. 3. Correlation between agar gel method (Rowe, 1961) and Sephadex column method for serum haptoglobin estimation.

Hb B.C. = Haemoglobin-binding capacity in $\mathrm{mg} . / 100 \mathrm{ml}$.
On Sephadex dextran gels the rate of elution of proteins is dependent on molecular size (Porath, $\delta$ 1962). Since human haptoglobin is present as a number of allelic forms which vary in molecularo size (Laurell, 1960), it would be expected that the precise point of elution of the complex would varyo in the different genotypes. As the haptoglobin molecules probably exist in the range of molecularos weight 89,000 to 220,000 (Herman-Boussier, Cloarec, $N$ and Cheftel, 1962), and haemoglobin binding is $\mathrm{\omega}_{\mathrm{H}}$ mole for mole, the complex would be expected to $\sigma$ vary in molecular weight from 156,000 to 310,000 . G.100 Sephadex does not resolve proteins in this? molecular range and molecules of this size will all $\stackrel{\Phi}{+}$ be eluted in the first peak of protein, while free haemoglobin will appear just after the albumin peak, $\overline{0}$ therefore little variation in position would be $\mathbb{\odot}$ expected by this method. This material is therefore $\overrightarrow{\mathbb{D}}$ better than G.200, in which partial resolution of the 


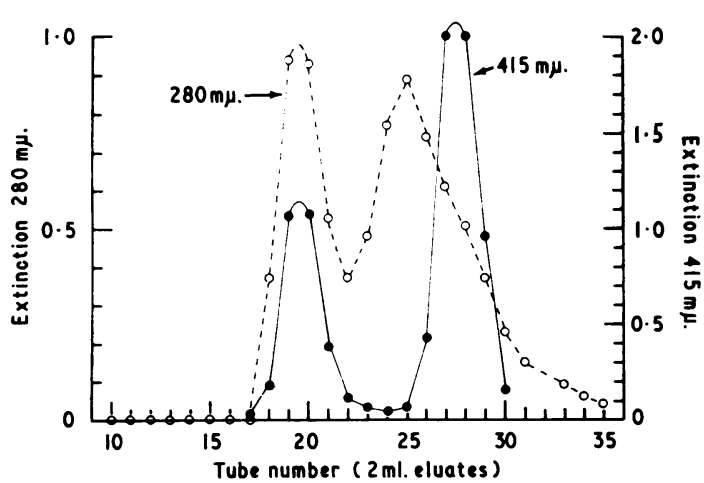

FIG. 4. Comparison of the elution pattern of haemoglobin/ haptoglobin complex and free haemoglobin with that of total protein $(\bigcirc \ldots .-$.$) .$

Sephadex $G .100$ column $\left(60 \times 1 \frac{1}{2} \mathrm{~cm}.\right)$

$2 \mathrm{ml}$. $1 / 5$ diluted serum $+0.1 \mathrm{ml}$. haemoglobin solution (= $1.4 \mathrm{mg} . \mathrm{Hb})+5 \mathrm{mg}$. sodium chloride, eluted with sodium chloride solution $(2 \mathrm{~g} . / 100 \mathrm{ml}$.).

Extinction at $415 \mathrm{m \mu}-$ (haemoglobin)

Extinction at $280 \mathrm{m \mu} \bigcirc \ldots$ - . - $\bigcirc$ (protein)

complexes produces a very broad band of elution of protein-bound haemoglobin. This has been borne out in practice (Fig. 4).

For any given column dimensions the point of elution of the various proteins is constant. Although the collection of many small aliquots has been used to develop the method described here, it should be relatively easy to devise a method in which continuous monitoring of the effluent, or collections of larger fractions would enable the procedure to be fully automated.

Although the variations in serum haptoglobin levels have been fairly extensively studied, the estimation is only currently in routine use for the detection of low levels in the diagnosis of haemolytic anaemia. Wide variations in serum levels occur in a range of diseases (Nyman, 1959), and very high levels are found in association with infection, injury, and the nephrotic syndrome; low levels may be found in some forms of liver disease, but not in association with reabsorption of blood pigments from an internal haemorrhage, when normal serum haptoglobin levels are associated with protein-bound haematin and a positive Schumm test (Northam, Rowe, and Winstone, 1963).

The advent of a simple reproducible method of estimation should lead to a much wider availability of this estimate in clinical practice, and to a greater knowledge of the significance of variations in serum level in disease.

\section{REFERENCES}

Aber, G. M., and Rowe, D. S. (1960). Brit. J. Haemat., 6, 160. Connell, G. E., and Smithies, O. (1959). Biochem. J., 72, 115.

Dacie, J. V. (1956). Practical Haematology, 2nd ed. Churchill, London. Herman-Boussier, M., Cloarec, L., and Cheftel, R. I. (1962). Nouv. Rev. franc. Hémat., 2, 455.

Jayle, M. F. (1951). Bull. Soc. Chim. biol. (Paris), 33, 876.

Laurell, C. B., and Nyman, M. (1957). Blood, 12, 493.

(1960). In The Plasma Proteins, vol. I, edited by F. W. Putman, p. 358. Academic Press, New York.

Neale, F. C., Aber, G. M., and Northam, B. E. (1958). J. clin. Path., 11, 206.

Northam, B. E., Rowe, D. S., and Winstone, N. E. (1963). Lancet, $1,348$.

Nyman, M. (1959). Scand. J. clin. Lab. Invest. suppl. 39.

Porath, J. (1962). Advanc. Protein Chem., 17, 209.

Rowe, D. S. (1961). J. clin. Path., 14, 205. 